\title{
Dark-Induced Barley Leaf Senescence - A Crop System for Studying Senescence and Autophagy Mechanisms
}

\author{
Ewelina Paluch-Lubawa, Ewelina Stolarska and Ewa Sobieszczuk-Nowicka* \\ Department of Plant Physiology, Faculty of Biology, Adam Mickiewicz University in Poznań, Poznań, Poland
}

OPEN ACCESS

Edited by:

Péter Poór,

University of Szeged, Hungary

Reviewed by:

Klaus Humbeck,

Martin Luther University

of Halle-Wittenberg, Germany

Martina Spundova,

Palacký University, Czechia

*Correspondence:

Ewa Sobieszczuk-Nowicka

evaanna@amu.edu.pl

Specialty section:

This article was submitted to

Plant Physiology,

a section of the journal

Frontiers in Plant Science

Received: 30 November 2020

Accepted: 23 February 2021

Published: 15 March 2021

Citation:

Paluch-Lubawa E, Stolarska E and Sobieszczuk-Nowicka E (2021)

Dark-Induced Barley Leaf

Senescence - A Crop System for Studying Senescence and Autophagy

Mechanisms.

Front. Plant Sci. 12:635619 doi: 10.3389/fpls.2021.635619
This review synthesizes knowledge on dark-induced barley, attached, leaf senescence (DILS) as a model and discusses the possibility of using this crop system for studying senescence and autophagy mechanisms. It addresses the recent progress made in our understanding of DILS. The following aspects are discussed: the importance of chloroplasts as early targets of DILS, the role of Rubisco as the largest repository of recoverable nitrogen in leaves senescing in darkness, morphological changes of these leaves other than those described for chloroplasts and metabolic modifications associated with them, DILS versus developmental leaf senescence transcriptomic differences, and finally the observation that in DILS autophagy participates in the circulation of cell components and acts as a quality control mechanism during senescence. Despite the progression of macroautophagy, the symptoms of degradation can be reversed. In the review, the question also arises how plant cells regulate stress-induced senescence via autophagy and how the function of autophagy switches between cell survival and cell death.

Keywords: autophagy, cell death, cell survival, developmental senescence, senescence model, sources and sinks communication, stress-induced senescence

\section{INTRODUCTION}

In plants, senescence is a highly controlled and active process requiring global metabolic reprogramming, aimed at organized disintegration and remobilization of valuable resources (Himelblau and Amasino, 2001; Maillard et al., 2015). It is a fundamental aspect of plant development, necessary to optimize resource allocation and promote phenotypic plasticity to adapt to the environment under restricted conditions. Being photoautotrophic, plants rely mainly on their leaves to support their growth. Leaves are organs optimized for the use of light energy and the subsequent production of photosynthates while minimizing total anabolic cost. In terms of stress conditions, this can be beneficial to the plant if a leaf which is not photosynthetically productive undergoes senescence, thus making its resources available to other organs. Therefore, the induction of senescence must be strictly controlled to avoid unnecessary activation only under temporarily unfavorable conditions. In congruence with the importance of leaves in photosynthesis, light plays an essential role in regulating leaf senescence. For many species of plants, a lack of light in the form of strong shading or darkening of the leaves leads to rapid senescence, especially when only parts of the plant are affected (reviewed in Liebsch and Keech, 2016). 
Dark-induced senescence has been used experimentally as an easy way to study the progress of leaf senescence. However, detailed studies of gene expression patterns have revealed discrepancies between the dark-induced and developmentally controlled process (Becker and Apel, 1993; Lee et al., 2001; Buchanan-Wollaston et al., 2005; van der Graaff et al., 2006; Guo and Gan, 2012; Roberts et al., 2017). The relevance of investigations on dark-induced senescence has often been discussed, but shade is an important scenario for crop yields in dense canopies. Under field conditions, crops are likely to benefit from the lower leaves of the canopy undergoing senescence and thus re-mobilizing nutrients for use in the upper, photosynthetic parts of the plants. Dark-induced leaf senescence (DILS) results in a clear loss of chlorophyll, disassembly of cellular elements and a lack of photosynthetic activity, none of which can be distinguished from the age-dependent natural senescence (Buchanan-Wollaston et al., 2003, 2005). However, the lack of coordinated cell development within a single leaf introduces complexity in the leaf senescence study. Thus, induced senescence, which directs a synchronous process, like darkinduced senescence, has become relevant (Kleber-Janke and Krupinska, 1997; Gepstein et al., 2003; Lin and Wu, 2004; Feller et al., 2008; Christiansen and Gregersen, 2014; SobieszczukNowicka et al., 2015, 2016; Law et al., 2018). It also eliminates misleading factors that coincide with developmental senescence, such as bolting or flowering (Gregersen et al., 2008). Widely used experimental setups to study dark-induced senescence in barley are (i) detached leaf in darkness (e.g., Becker and Apel, 1993; Legocka and Zajchert, 1999; Chrost and Krupinska, 2000; Rosiak-Figielek and Jackowski, 2000; Chrost et al., 2004; Żelisko and Jackowski, 2004; Conrad et al., 2007; Sobieszczuk-Nowicka et al., 2009, 2015; Kucharewicz et al., 2017; Janečková et al., 2019) (ii) whole plant in darkness (e.g., Kleber-Janke and Krupinska, 1997; Krause et al., 1998; Roulin et al., 2002; Simova-Stoilova et al., 2002; Arnao and Hernández-Ruiz, 2009; Jajić et al., 2014; Avila-Ospina et al., 2015; Zmienko et al., 2015; SobieszczukNowicka et al., 2016, 2018), and (iii) individually darkened attached leaf, whilst the rest of the plant remained in a normal photoperiod condition (e.g., Rolny et al., 2011; Shi et al., 2012; Christiansen et al., 2016). As the course of the senescence process is related to plant species, plant developmental stage, and plant environmental conditions these treatments cannot be considered the same. However, darkness induces some series of transformations at the cytological, biochemical and molecular levels common within these setups. These features are summarized in Table $\mathbf{1}$ and are discussed in the context of the transformations that occur in the DILS program (SobieszczukNowicka et al., 2018). DILS program setup are barley seedlings grown in growth chamber for 7 days under controlled conditions (day/night $16 / 8 \mathrm{~h}, 23^{\circ} \mathrm{C}$, light intensity $150 \mu \mathrm{mol} \mathrm{m}{ }^{-2} \mathrm{~s}^{-1}, 60 \%$ humidity). Pots with seedlings on seventh day of growth are transferred to dark conditions to initiate senescence.

The genome resources available for Arabidopsis have made it a very attractive model of identification and functional analysis of genes regulated by senescence (Buchanan-Wollaston et al., 2003, 2005; Breeze et al., 2011). However, in many plants, such as barley, the removal of developing flowers and pods significantly extends the life of their leaves, while in Arabidopsis, male-sterile mutants or plants from which developing bolts have been removed do not extend the life of leaves. Because of these differences, cereal leaves must be used as an equivalent to the Arabidopsis model for leaf senescence studies in cereal (Zea mays - Smart et al., 1995; Oryza sativa - Lee et al., 2001; Triticum aestivum - Uauy et al., 2006; and Hordeum vulgare - Kleber-Janke and Krupinska, 1997; Jukanti et al., 2008; Christiansen and Gregersen, 2014; Avila-Ospina et al., 2015; Springer et al., 2015; Wehner et al., 2015; Sobieszczuk-Nowicka et al., 2018). Clear differences in the senescence program of Arabidopsis compared to monocotyledonous plants were found. The senescence in cereals is generally regulated at the single leaf level. Nutrients from older leaves are remobilized for younger leaves and ultimately for the flag leaf, thus contributing to the nutrients necessary for the development of the grain. Cereal leaves have a meristem base, the leaf tip consists of older cells, and younger ones are concentrated at the base of the leaf. This cell organization makes it easier to differentiate the progression of senescence (Gregersen et al., 2008).

Understanding both dark- and shade-induced senescence is of great economic importance as it can significantly shorten the shelf life after harvest and lead to significant crop losses (Gan and Amasino, 1997; Nam, 1997; Buchanan-Wollaston et al., 2003; Liu et al., 2015; Schippers et al., 2015). Significant progress has been made in our understanding of leaf senescence and its basic regulation at the molecular level over the last decades. Furthermore, a theoretical model (senescence window concept) has emerged which explains how senescence competence is determined during leaf development and how internal and external factors are integrated with age to determine the duration of senescence (Jing et al., 2002). Also, much of the fundamental knowledge about senescence regulation has been tested in cultivated plant species for its potential use to improve productivity. This includes stay-green features (Thomas and Ougham, 2014) and pSAG12:IPT technology (Gan and Amasino, 1995). Further clarification of the senescence window concept and a change that gives plants competence for senescence will allow for more targeted strategies to manipulate senescence by focusing on the different phases of development. Many researchers have discovered that it is extremely difficult to try to separate senescence regulation paths from the stress response because the genetic program underlying senescence is largely in line with the plant defense program. Therefore, changing one senescence parameter can also reduce plant tolerance to stress. Integrative research is needed that not only focuses on the role of single genes in the onset of senescence but also examines the conditions under which manipulation of the senescence process is beneficial for crop yield and nutritional value (a concept reviewed in Schippers et al., 2015).

This review will address the studies that allow showing (i) the survival strategy behind dark-induced senescence in barley plant and (ii) dark-induced barley leaf senescence to be used as a model, referred to in the manuscript also as DILS program, to examine leaf senescence. The idea of a program as applied to living systems has been taken from computer science. The system is built in 
TABLE 1 | Overview of the experimental setups of dark-induced barley leaf senescence assays employed through the different studies cited in this review, and comparison of assessed parameters against DILS (Sobieszczuk-Nowicka et al., 2018).

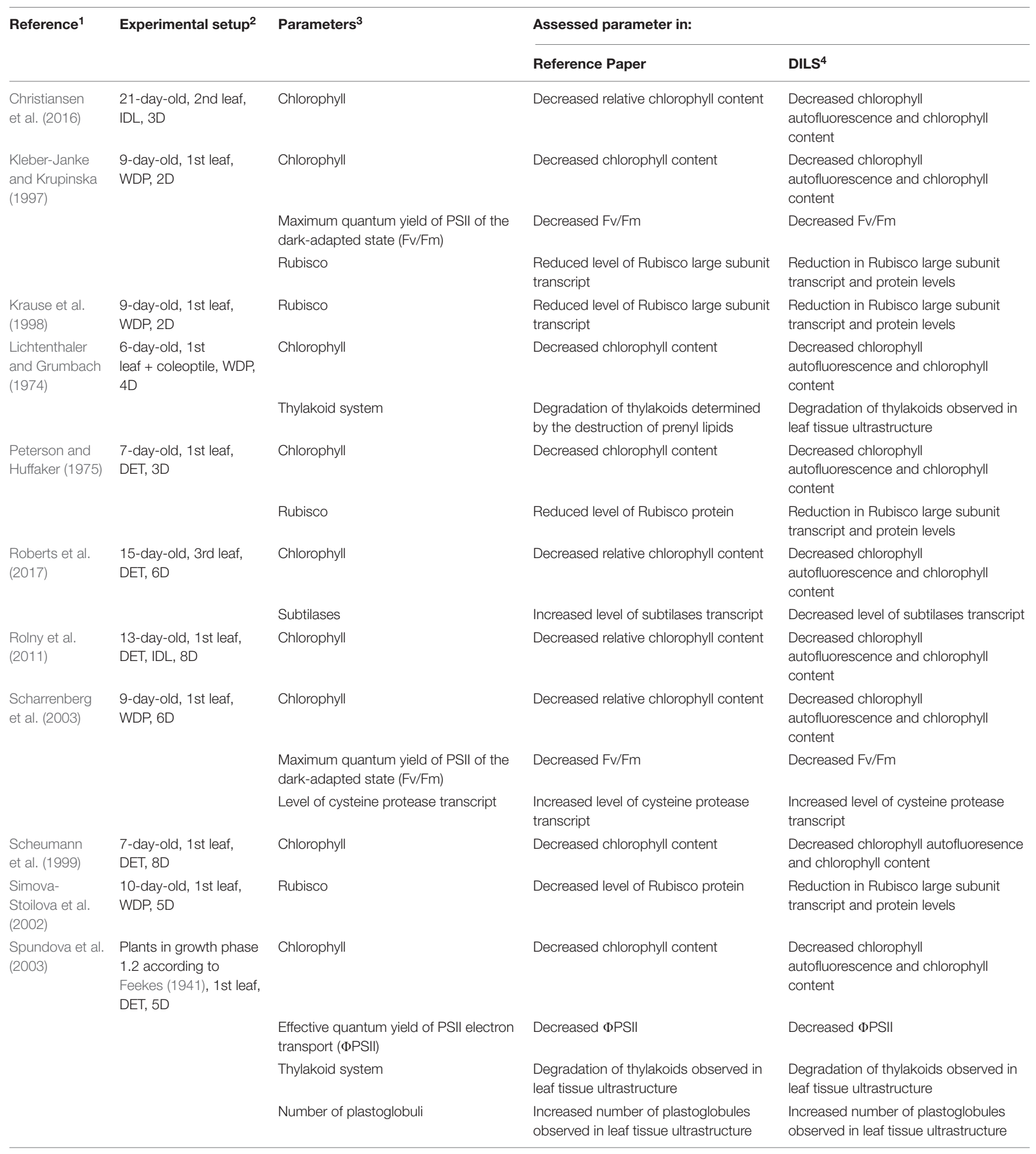


TABLE 1 | Continued

\begin{tabular}{|c|c|c|c|c|}
\hline Reference $^{1}$ & Experimental setup ${ }^{2}$ & Parameters $^{3}$ & Assessed parameter in: & \\
\hline $\begin{array}{l}\text { Wood et al. } \\
(1998)\end{array}$ & $\begin{array}{l}\text { 7-day-old, 2nd leaf, } \\
\text { WDP, 5D }\end{array}$ & Single strand nucleases (SSN) & Increased SSN enzyme activity & Increased level of SSN transcript \\
\hline
\end{tabular}

${ }^{1}$ Literature references to dark-induced barley leaf senescence as given in the main text.

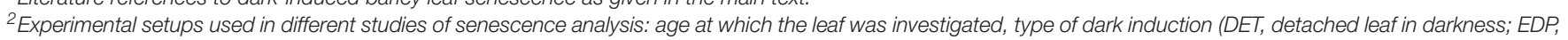
whole plant in darkness; IDL, individually darkened attached leaf), the number of days in darkness (D) and days of light re-exposure (L).

${ }^{3}$ The parameters that were used in the study of DILS models (Sobieszczuk-Nowicka et al., 2018).

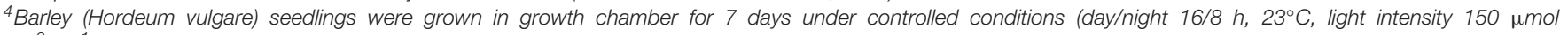

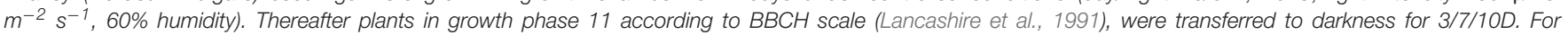

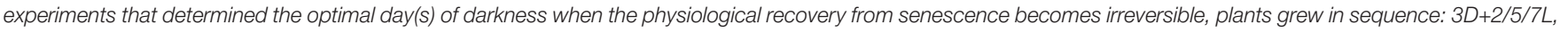
$7 D+2 / 5 / 7 L$, and $10 D+2 / 5 / 7 L$.

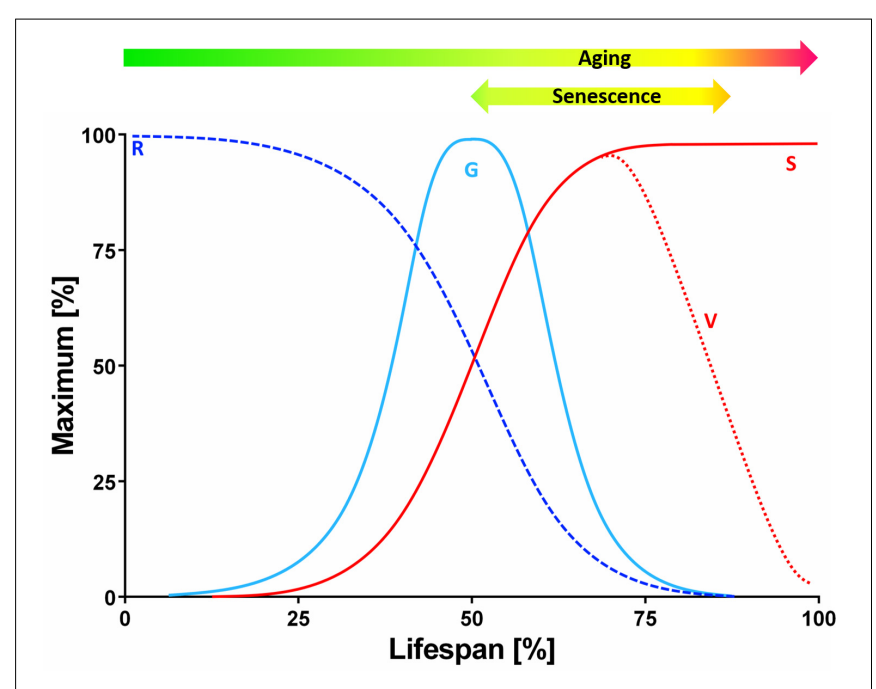

FIGURE 1 | Theoretical curves of plant growth and viability. The pattern of cell mass, tissue, organ, whole plant or population growth in size (S) follows a typical sigmoidal curve. The instantaneous growth rate $(G)$ is maximal at the point of breakdown of the $S$ curve, whereas the relative growth rate $(R=\mathrm{G} / \mathrm{S})$ slopes down systematically over time. The viability of the plant $(V)$ starts to decline gradually after the peak of $G$. The decreasing $V$ is antagonistic to senescence. It should be noted that aging refers, in this context, to transition in time (not deterioration) and it comprises the period of senescence and the final phase of declining $V$ (but it is not limited or defined by these) (modified from Thomas, 2013).

a particular way, and so, always starts and fails in more or less the same manner.

We present transcriptomic, cytological, and physiological data that reveal events in barley DILS program, differences from developmental senescence, the time limit for dark-to-light transition for reversal of the senescence process, and progression of senescence through autophagy into the PCD phase.

Senescence, aging, and death are topics that notoriously attract semantic disputes. The review, will begin with a brief discussion about the terminology used here. Growth in size (S) of a cell mass, tissue, organ, whole plant or population follows a typical sigmoid pattern (Figure 1). The instantaneous growth rate $(\mathrm{G})$ is maximal at the point of breakdown of the $S$ curve. The relative growth rate $(R=\mathrm{G} / \mathrm{S})$ decreases gradually over time. The declining life span (V) is antagonistic to senescence. Aging refers to changes (not deterioration) over time and includes, but is not limited to or defined by, the senescence period and the final phase of $\mathrm{V}$ decline. Senescence thus generally refers to the process or condition of growing old (from the Latin senescere, to grow old). Senescence, according to the current physiological understanding, is the developmental phase that: (i) constitutes an episode of transient differentiation at the termination of growth; (ii) may or may not be succeeded by death; and (iii) is completely dependent on cell viability and specific gene expression (Thomas, 2013).

\section{PROCESSES IN CHLOROPLASTS ARE EARLY TARGETS OF DARK-INDUCED BARLEY LEAF SENESCENCE}

The first symptoms of leaf senescence are chloroplast degeneration (Dodge, 1970; Gepstein et al., 2003; Lim et al., 2007) and the decline in photosynthesis associated with it (Krieger-Liszkay et al., 2019). The earliest effects of DILS are visible in the chloroplast ultrastructure within the first $72 \mathrm{~h}$ of the plant's stay in the dark. During DILS program leaf yellowing is observed, and is further identified as a result of chlorophyll (Chl) degradation, which is associated with a decrease in its autofluorescence (Sobieszczuk-Nowicka et al., 2018). Also the works of, Lichtenthaler and Grumbach (1974), Peterson and Huffaker (1975), Rolny et al. (2011), Kleber-Janke and Krupinska (1997), Scheumann et al. (1999), Scharrenberg et al. (2003), Spundova et al. (2003), and Roberts et al. (2017) on barley showed a significant decrease in chlorophyll in the early stages of dark-induced barley leaf senescence. The loss of $\mathrm{Chl}$ indicates the remobilization of nitrogen compounds and is accompanied by an increase in flavonoids (Flv). Most likely, this is due to the fact that, in the absence of nitrogen, excess carbon is used to synthesize polyphenols, which include Flv (Cartelat et al., 2005). Cytological studies on barley chloroplasts senescing in dark show a gradual degradation of the thylakoid system, an increase in the size and number of plastoglobuli, and, as a result, the breakdown of chloroplasts (Lichtenthaler and Grumbach, 1974; Spundova et al., 2003; Sobieszczuk-Nowicka et al., 2018). In parallel, in dark-induced senescing leaves of barley, changes in parameters determining photosynthetic quantum conversion are observed. The parameter of chlorophyll fluorescence decrease ratio (Rfd) called the vitality index ratio is dynamically falling in 
the early stage of DILS model in barley, which is why it is considered a significant marker parameter for stress caused by darkness. The effective quantum yield of PSII electron transport ( PPSII) is characterized by lesser sensitivity, decreasing less intensely than Rfd (Sobieszczuk-Nowicka et al., 2018). Both Rfd and $\Phi$ PSII are referred to as net $\mathrm{CO}_{2}$ assimilation rates (Fracheboud and Leipner, 2003; Baker and Oxborough, 2004; Lichtenthaler et al., 2005; Wong et al., 2014). The remaining parameters slightly decreased during DILS model: maximum quantum yield of PSII of the dark-adapted state (Fv/Fm), maximum quantum yield of PSII in the light-adapted state $\left(\mathrm{Fv}^{\prime} / \mathrm{Fm}^{\prime}\right)$, and photochemical quenching of $\mathrm{Chl}$ fluorescence (qP). All parameters of the values listed above showed a decrease only in the advanced stage of DILS (SobieszczukNowicka et al., 2018). A decrease in the Fv/Fm and DPSII parameters during senescence was also demonstrated in other studies on dark induced leaf senescence of barley (Kleber-Janke and Krupinska, 1997; Scharrenberg et al., 2003; Spundova et al., 2003).

van Doorn and Yoshimoto (2010) stated that the terminal, senescing stage of a plant cell may be reversed if the functions of the chloroplasts can be restored. To assess the limits of the ability of senescence reversal for the DILS model, it was measured the photosynthetic quantum conversion parameters and nitrogen status in barley leaves subjected to light reexposure after various periods of dark incubation. During this process of re-exposure to light, it was observed that the parameters such as $\mathrm{Fv} / \mathrm{Fm}, \mathrm{Fv}^{\prime} / \mathrm{Fm}^{\prime}, \mathrm{qP}$, Chl. Flv and NBI that had gradually decreased during DILS program began to recover. The Rfd and $\Phi$ PSII parameters were also restored, although with a delay. This reversal occurred in samples exposed to darkness until, but not beyond, day 7, with dark incubation lasting longer than day 7 , causing an irreversible decline in all the measured parameters (Sobieszczuk-Nowicka et al., 2018). Also for each analyzed indicator, a 2-day period of light reexposure does not suffice to return the level to that of the light control. This suggests that, in spite of the high potential of chloroplasts to restore the photochemical efficacy of solar energy conversion, the energy conversion of excitation and/or the use of potential energy, coupled with the transport of electrons, may be restricted by some unidentified factor whose reversibility is compromised.

\section{RUBISCO IS THE LARGEST REPOSITORY OF RECOVERABLE NITROGEN IN BARLEY LEAF SENESCING IN DARKNESS}

Mature leaves are the place of carbon (C) assimilation in the process of photosynthesis. The leaves are the sources, which means that the metabolism precursors are exported from them where they are needed: to the sinks, such as developing seeds (Lim et al., 2007; Thomas, 2013; Law et al., 2018). Sources and sinks communicate using the vascular system. At the beginning, young, expanding leaves are developing as sinks, but when they fully develop, they become sources. Leaves mainly export C obtained from photosynthesis, but when the leaves begin to grow old and cease to photosynthesize, they become sources of nitrogen $(\mathrm{N})$ derived from the decomposition of leaf tissue proteins. The beginning of leaf senescence can be considered the moment of transition: from the assimilation of nutrients, to their remobilization. In other words, it is the point where leaves cease to be the sources of C, and become the sources of N (Masclaux et al., 2000; Thomas, 2013; Law et al., 2018). Therefore, leaves are, on the one hand, the location of $\mathrm{C}$ assimilation, and on the other, the $\mathrm{N}$ storage place. Behind this leaf bifunctionality is the main chloroplast protein, ribulose-1,5-bisphosphate carboxylase/oxygenase - Rubisco (Thomas, 2013). Rubisco is a photosynthetic enzyme that binds $\mathrm{C}$ from $\mathrm{CO}_{2}$ and is also a reserve of mobilizable $\mathrm{N}$ as Rubisco proteins contain up to $35 \%$ of total leaf nitrogen and up to $70 \%$ of chloroplasts' nitrogen (Hörtensteiner and Feller, 2002; Krieger-Liszkay et al., 2019). Storage proteins, including Rubisco, are characterized by either a very low level, or no simultaneous protein synthesis and decomposition. When the leaves are young and growing, there is a very high level of Rubisco synthesis, and only once the synthesis stops does the protein breakdown begin (Thomas, 2013). In general, Rubisco degrades rapidly during any type of senescence (Hörtensteiner and Feller, 2002; Lan and Miao, 2019). In dark-induced senescence of barely leaves, this was confirmed by Peterson and Huffaker (1975), SimovaStoilova et al. (2002), and Roberts et al. (2017). The level of Rubisco protein, drop significantly throughout DILS model (Sobieszczuk-Nowicka et al., 2018). This decrease was correlated with the level of expression of Rubisco large subunit gene, which decreased significantly during early phase of the process (Sobieszczuk-Nowicka et al., 2018). Also Krause et al. (1998) and Kleber-Janke and Krupinska (1997) has reported that the transcript levels of small and large subunits of Rubisco were significantly decreased during the dark-induced senescence of the barley leaves.

In contrast, the second marker protein for chloroplasts' biochemistry - PSII reaction center D1 protein photosystems (Mattoo et al., 1989) - is quite stable and only slightly decreases in the late phase of DILS (Sobieszczuk-Nowicka et al., 2018). It might be due to the fact that the system complexes are active up to point of no return. Interestingly, the level of $P S B A$ genes encoding D1 protein dropped in the early phase of DILS program. The difference between the decline in D1 protein and its transcript seems to stem from the fact that the D1 protein is under posttranscriptional control (SobieszczukNowicka et al., 2018). These differences in the degradation rate of the two chloroplast marker proteins, Rubisco and D1, in the early stage of DILS could be part of the stress adaptation strategy, as a result of which the degradation of the highly important ATP synthesis machinery in dark-induced senescence is delayed (Krupinska et al., 2012). This sequence of events is supported by the remaining microarray results of barley DILS program, which show a high level of ATP-dependent metabolism of amino acids, fatty acids, hormones and pigments, and active complexes of photosystems up to the time when 
senescing in darkness leaves entering the point of no return (Sobieszczuk-Nowicka et al., 2018).

\section{MORPHOLOGICAL CHANGES OF BARLEY LEAVES SENESCING IN DARKNESS OTHER THAN THOSE DESCRIBED FOR CHLOROPLASTS AND METABOLIC MODIFICATIONS ASSOCIATED WITH THEM}

In plant cells during dark-induced senescence chromatin condensation and nuclear fragmentation occur. At the beginning of senescence, the ultrastructure of the nucleus does not differ significantly from mature leaves. The condensation of chromatin typically starts at the periphery of the nucleus and moves inward (Sakamoto and Takami, 2014; Liu et al., 2017). During the early stages of DILS, the ultrastructure of the nucleus of barley does not differ from mature leaves. However, with the progression of senescence the shape and structure of the nucleus becomes more irregular. These changes are accompanied by DNA fragmentation (Sobieszczuk-Nowicka et al., 2018). Similar results were also reported for Phaseolus vulgaris (Lambert et al., 2017) and Petroselinum crispum (Canetti et al., 2002). The nuclear breakdown is accompanied by the release of nucleases and proteases, acidification of the cytoplasm, and rapid degradation of nucleic acids and proteins (Obara et al., 2001; Kuriyama and Fukuda, 2002), which can be a source of carbon and nitrogen. The Bnucl gene that encodes a BNUC1 endonuclease is generally associated with senescence (Sakamoto and Takami, 2014) and is a marker of DNA degradation of DILS. DILS program is associated with very high induction of Bnucl gene expression (SobieszczukNowicka et al., 2018). Wood et al. (1998) demonstrated in dark incubated barley an increase in activity of single strand preferring nuclease (SSN), which also is overexpressed in later stage of DILS.

In addition to changes in nucleus organization, changes in the tonoplast's topology occur during dark-induced senescence. At the start of senescence, invagination of the tonoplast and cytoplasmic fragments near the vacuole can be observed. Together with these, shrinking of the protoplast is notable. With the progression of DILS in barley leaf cells, gaps in the cell membrane appear and eventually the tonoplast ruptures (Sobieszczuk-Nowicka et al., 2018). This consequently leads to the release of lytic enzymes and degradation of the nucleus and mitochondria. Usually, the rupture of the tonoplast is the final step of senescence ending in PCD (Rogers, 2015).

Since chloroplasts are one of the first to be degraded, the senescing cells must rely on mitochondria to obtain energy (Keech et al., 2007). Keech et al. (2007) reported that the morphology and abundance of these organelles change during dark-induced senescence in leaves of Arabidopsis thaliana. Mitochondria then are less abundant and rounder or even almost spherical. The decrease in the number of mitochondria can also be observed in different ways in different parts of the leaf, i.e., mesophyll compared to epidermal cells. Interestingly, mitochondrial numbers in stomata are not affected by darkinduced senescence (Keech et al., 2007), which takes place in developmental senescence, as was shown for Vitis vinifera (Ruberti et al., 2014). Also, during the final stages of the process, Keech et al. (2007) reported a cellular distribution of the organelle changes. Mitochondria clump together in loose aggregates in comparison to the relatively homogeneous distribution in control Arabidopsis plants (Keech et al., 2007). When the source of sugars is depleted in leaves kept in the dark, amino acids become a source of nutrients to sustain mitochondria respiration. Ammonium released in this way is assimilated by cytosolic glutamine synthetase 1 (GS1) isoforms and remobilized (Masclaux et al., 2000, 2001). The mitochondrial glutamate dehydrogenase that is known to catabolize glutamate to provide 2-oxoglutarate (2-OG) to the mitochondria is one of the catabolic enzymes releasing ammonium and 2-OG during DILS (Masclaux-Daubresse et al., 2006; Araujo et al., 2010; Kleessen et al., 2012). During DILS in barley one can also observe up-regulation of other enzymes responsible for remobilization of degraded nitrogen compounds such as cysteine and aspartyl proteases, ubiquitination enzymes, Hsp70, cytosolic Gln synthetase (Gln-1-3 isoform of low affinity to ammonia), and Orn cycle enzymes (P5C dehydrogenase, arginase, acetyl-Orn transaminase) (Sobieszczuk-Nowicka et al., 2018). Also during this specific time, lipid catabolism increases, which suggests that lipid degradation may participate in the production of energy, which in turn involves succinate synthesis within glyoxysomes and export thereafter to mitochondria (Sobieszczuk-Nowicka et al., 2018). Mitochondrial metabolism during DILS in barley is demonstrated to be important in relocation of recycled carbon and nitrogen substrates which come from proteins, lipids and other cellular components, since after crossing the point of no return the deterioration processes coupled with respiration intensify, which is observed by e.g., overexpression of genes involved in vesicle recycling (signalosome complex, SNARE complex or vesicle-fusing ATPase) (Sobieszczuk-Nowicka et al., 2018). Increased expression of key genes of gluconeogenesis and glycolysis along with upregulation of glyoxysomal enzymes are also supportive of recycling of substrates (Hollmann et al., 2014).

\section{AUTOPHAGY AND SENESCENCE OCCUR SYNCHRONOUSLY IN DARK-INDUCED BARLEY LEAF SENESCENCE}

During plant growth and development, damaged or aging cells' components undergo degrading processes inside vacuoles in a process called autophagy. Autophagy does not occur at a very high level under physiological conditions, and it is a housekeeping process during normal conditions, allowing the organism to adapt to changing environmental conditions and allowing its survival and prolonging its life span (Avila-Ospina et al., 2014; Borek et al., 2017; Stefaniak et al., 2020). The process of autophagy is phylogenetically conserved, involving intracellular degradation where cytoplasmic compounds are 
broken down in the vacuole to supply basic components and energy to maintain essential functions. During autophagy also damaged cells and toxic compounds are utilized (van Doorn and Woltering, 2005; Janawad et al., 2012). As DILS is a process of transition from nutrient assimilation to nutrient remobilization (Buchanan-Wollaston et al., 2005), autophagy plays a key role in it. In plants, several types of autophagy can be distinguished, mainly microautophagy and macroautophagy (Bassham et al., 2006) as well as a third, plant-specific pathway, called megaautophagy (Floyd et al., 2015). Microautophagy consists of tonoplast invagination which results in engulfment of tonoplast and cytoplasmic components by intravacuolar vesicles and their uptake into the vacuole (Bassham et al., 2006; Sienko et al., 2020). Megaautophagy also leads to disintegration of cell contents using vacuolar enzymes, but the material is not taken up inside the vacuole. Instead, vacuolar hydrolases are released to the cytoplasm after permeabilization and disruption of the tonoplast (Hara-Nishimura et al., 2005; Bollhöner et al., 2012). In turn, macroautophagy begins with the appearance in the cytoplasm of an elongated vesicle (phagophore) composed of a single, bilayer lipid-protein membrane, which elongates and engulfs a fragment of the cytoplasm with cell organelles and/or protein complexes. The resultant autophagosome is then transported to the vacuole, where the cargo is hydrolyzed (Borek et al., 2015). Macroautophagy is responsible for maintaining standard function of the cell (Lamb et al., 2013). Hence, organized development of DILS requires effective recycling machinery which allows the correct development of a plant to be maintained. During dark-induced senescence, the increased degradation of macromolecules such as nucleic acids, proteins, and sugars, provides components for regulated recycling and reuse by other parts of the plant (Jing et al., 2003).

It was reported that Rubisco and its degradation products can be transported into vacuoles via Rubisco-containing bodies (RCBs) after darkness treatment (Chiba et al., 2003). Ishida et al. (2008) found that RCB targeting to the vacuole are autophagydependent. They also observed, using plants expressing both the GFP-ATG8 fusion marker specific for autophagosomes and autophagic bodies, and stroma-targeted RFP, co-localization of the two fluorescent markers within the vacuole (Ishida and Yoshimoto, 2008; Ishida et al., 2008).

In leaves senescing in darkness autophagy is apparent as small autophagic bodies in vacuoles, presence of autophagosomes in protoplasts and in the process of tonoplast rupturing. Also, a number of autophagy-related genes (ATGs) have been identified during dark-induced senescence, which are highly expressed during the progress of the process (Chung et al., 2009; Xia et al., 2012; Avila-Ospina et al., 2016; Sobieszczuk-Nowicka et al., 2018). In barley SobieszczukNowicka et al. (2018) showed that at the onset of DILS program the tonoplast membrane invaginates, small cytoplasmic fragments are near the vacuole and the cytoplasm shrinks, which indicates the involvement of microautophagy in the early stages of senescence. When DILS proceeds, leaf cells demonstrate cell membrane discontinuity, which indicates the processes of macroautophagy. However, even at this stage, the effects of DILS degradation processes have been shown to be reversible. In the final stages of DILS these processes are followed by megaautophagy, which is a rupture of the tonoplast and release of hydrolases. In consequence, organelles undergo progressive degradation and are localized in the center of the cell, and the intracellular compartmentation is lost due to the plasma membrane loosening. When megaautophagy occurs, the cell enters the "point of no return" after which degradation of the cell nucleus and mitochondria take place, and the cell proceeds into PCD, Sobieszczuk-Nowicka et al. (2018). Figure 2 summarizes the described stages of senescence occurring in barley cells during darkness, taking into account the characteristic autophagy types: micro-, macro-, and megaautophagy. Despite the progression of macroautophagy, the symptoms of degradation can be reversed, until megaautophagy occurs, showing a clear point of no return. Together with these changes a number of ATGs are upregulated as well as genes encoding vacuolar-processing enzymes (i.e., $\alpha V P E$ and $V P E 2 c$ ), whose expression increases with the progression of senescence. VPE genes are involved in ATG-independent alternative cell degradation pathways via senescence-associated vacuole formation. During dark-induced senescence a vital role is played by these $0.5-0.8 \mu \mathrm{m}$ vacuoles (SAVs). SAVs have been identified in the senescent leaves of several plants, including soybean, Arabidopsis, and tobacco, but are absent in non-senescing leaves (Martinez et al., 2008a,b). There are soluble proteins (such as Rubisco) and resident proteases (such as senescence-specific SAG12) in the acid lumen of these vacuoles (Pascual et al., 1994; Otegui et al., 2005; Martinez et al., 2008a,b). In DILS relative to the expression of $\alpha V P E$ and $V P E 2 c$, that of the known senescence-activated marker gene Cys protease (SAG12) was minimally induced (Sobieszczuk-Nowicka et al., 2018).

Turnover of macromolecules via selective autophagy may contribute to cell homeostasis, nutrient recycling, and clearance of damaged structures during DILS. The fact that autophagy might be important in $\mathrm{N}$ mobilization in the course of developmental leaf senescence of barley has been proposed before (Hollmann et al., 2014). We do not know the mechanisms that condition the metabolic reprogramming that directs to or leads out leaf cells senescing in darkness from the PCD pathway, switching cells between survival and death. However, we know that cell death occurs by suppressing macroautophagy and triggering megaautophagy. It is possible that VPEs are mediators of the crosstalk between senescence-dependent autophagy and PCD (Patel et al., 2006; Floyd et al., 2015; Wang et al., 2018). Supporting the hypothesis that autophagy works to keep cells healthy, controlling the cell component turnover during darkinduced senescence, is the fact that plants with low autophagic activity, i.e., Arabidopsis mutants, are more susceptible to stress and exhibit premature senescence symptoms and cell death (Phillips et al., 2008). The efficiency of regulation of autophagic processes is a symptom of the vitality of senescing cells, which at each stage must hold the ability to maintain homeostasis. Thus, we suggest that a critical step that determines the point of no return in DILS model is macroautophagy control. 


\section{Dark-Induced Leaf Senescence (DILS)}

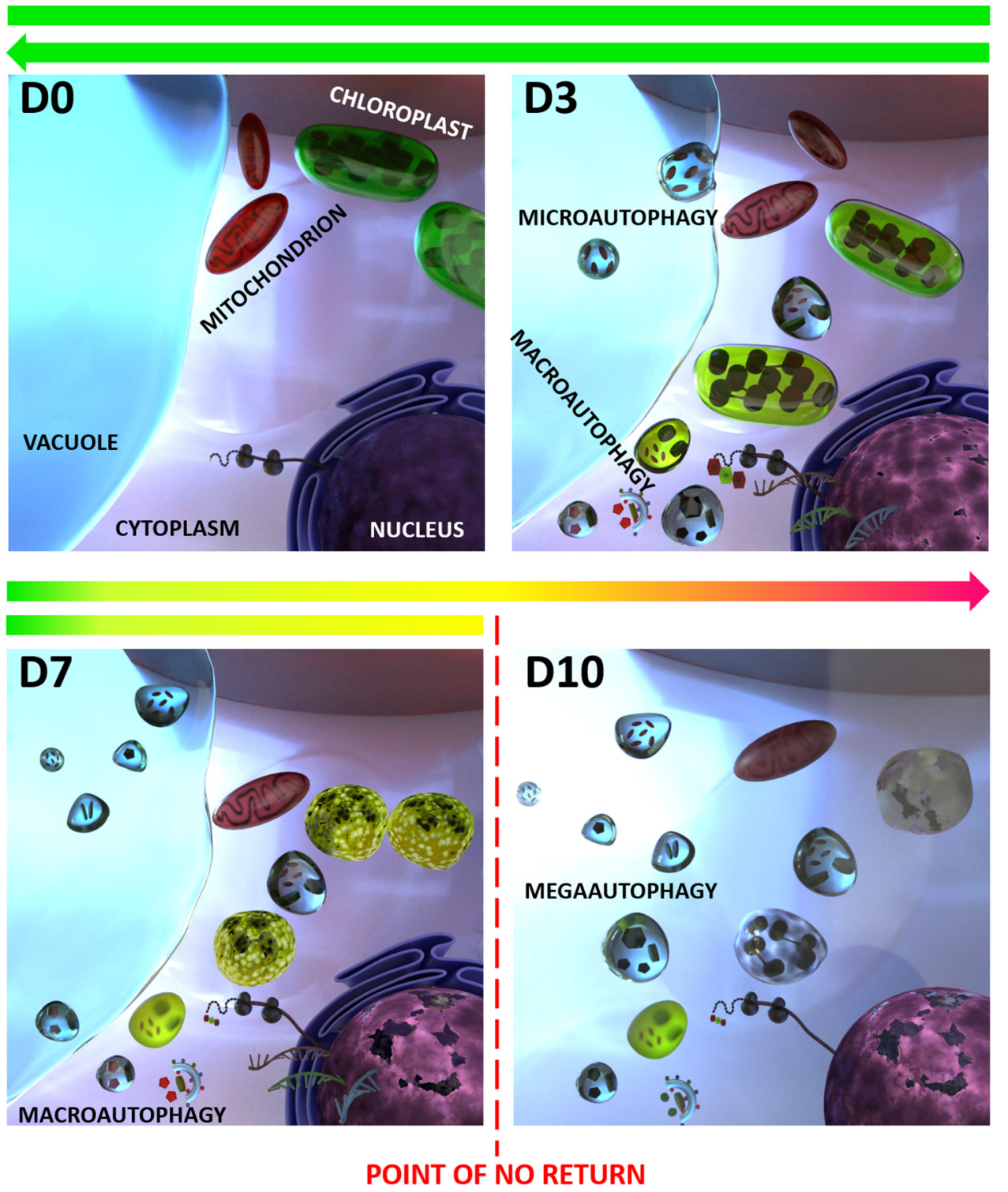

FIGURE 2 | Dark-induced leaf senescence (DILS) model vs. autophagy. D0 stands for control, D3 to D10 stand for days of senescence. A critical time limit was identified when it is possible to reverse the leaf senescence and prevent cell death. It was found that in DILS autophagy participates in the circulation of cell components and acts as a quality control mechanism during senescence. DILS is also a good model for studying the pathways of autophagy and programmed cell death. At each stage, DILS is accompanied by different types of autophagy: micro-, macro-, and mega-autophagy. Despite the progression of macroautophagy, the symptoms of degradation can be reversed. How the function of autophagy switches between cell survival and cell death is not known (modified from Sobieszczuk-Nowicka et al., 2018).

\section{DARK-INDUCED BARLEY LEAF SENESCENCE VERSUS DEVELOPMENTAL BARLEY LEAF SENESCENCE; TRANSCRIPTOMIC STUDY}

Large scale data analysis of barley DILS program using microarrays and re-analyzed data of Christiansen and Gregersen
(2014) and Hollmann et al. (2014) of developmental leaf senescence showed that genes expressed during DILS and developmental senescence show quite some similarities (Sobieszczuk-Nowicka et al., 2018). Genes encoding glyoxysomal citrate synthase (Hollmann et al., 2014) and mitochondrial succinate dehydrogenase (Christiansen and Gregersen, 2014) are common for both types of senescence and are upregulated during that time (Christiansen and Gregersen, 2014; Sobieszczuk-Nowicka et al., 2018). The regulation of 
these processes that allow for the organelles to gain energy seems to be necessary for the cell to replace the lack of ATP synthesis in chloroplasts for both dark-induced senescence and developmental senescence as the chloroplasts are dismantled at early stages of senescence, whereas mitochondria prevail until cell death (Peterson and Huffaker, 1975; Matile, 1992; Chrobok et al., 2016). Another resemblance is the downregulation of malate dehydrogenase, which is correlated with inhibition of glyceraldehyde-3-phosphate dehydrogenase in chloroplasts (Sobieszczuk-Nowicka et al., 2018). This enzyme functions as a fragment of the starch-degradation pathway that supports malate for other organelles in unstressed cells (Foyer et al., 2011). In both senescence models, low-affinity ammonia remobilization (by a cytosolic isoform of Gln synthetase 1 and Glu dehydrogenase) and Orn cycle transamination are also found to be activated (Sobieszczuk-Nowicka et al., 2018). Another similarity between DILS and developmental senescence of barley is common expression of some cysteine proteases (CPs). They are the most abundant enzymes associated with leaf senescence (Bhalerao et al., 2003; Parrott et al., 2010). Scharrenberg et al. (2003) have also reported that transcripts of CP HvSF42 (HvPap-1) increase in both senescence scenarios in barley. What is more, these authors demonstrated, that in both dark-induced and developmental senescence an NAC transcription factor (HvSF6/HvNAC008) is upregulated (Scharrenberg et al., 2003). HvSF6 was observed to be induced by the cross talk of jasmonic acid and ethylene in senescing barley in both developmental and dark-induced senescence (Scharrenberg et al., 2003). This observation was later confirmed by Christiansen et al. (2011), who identified 48 NACs in barley. This suggests the participation of NAC transcription factors as regulators of a range of processes in plant development and stress responses, senescence being one of them.

On the other hand, the most notable differences in gene medleys between DILS and developmental senescence were observed for signaling pathways which are activated by plant hormones, lipid catabolism, low-affinity ammonia remobilization, carbohydrate metabolism and DNA and RNA methylation. The differences between DILS and developmental senescence in the activity of carbohydrate and lipid metabolism enzymes were proven by recording the increase in expression of glycolytic glyceraldehyde-3-phosphate dehydrogenase and enolase in the first process but not in the other, whereas during DLS $\beta$-amylase and trehalose-6-phosphate synthase are up-regulated (Sobieszczuk-Nowicka et al., 2018). Similar results were obtained in Arabidopsis, in which lipid catabolism genes are considerably more upregulated during dark-induced senescence than in developmental (Buchanan-Wollaston et al., 2005). This causes an increase in beta-oxidation due to depletion of carbohydrates. In barley DILS there was noted upregulation of gluconeogenesis, to which the by-product of this pathway, phosphoenolpyruvate, can be directed. The pivotal enzyme of this process, pyruvate phosphate dikinase, is downregulated during developmental senescence. This is consistent with an increase in expression of Suc synthase in DILS, which was decreased during developmental senescence
(Sobieszczuk-Nowicka et al., 2018). A number of other crucial differences have also been revealed between these two processes. In DILS downregulation of C- and D-type phospholipase genes can be observed. Phospholipases are well-established enzymes taking part in both lipid catabolism and signaling pathways dependent on GTP, where they constrain the $\alpha$ subunit of G-protein coupled receptors (Fukami, 2002; Jenkins and Frohman, 2005). Another process differing between DILS and developmental senescence is the gibberellin synthesis pathway, which is upregulated in the former but not in the latter. But then, signaling through jasmonic acid and auxin seems to be crucial for developmental senescence as the overexpression of 3-ketoacyl-CoA thiolase and auxin response factor 19 is observed during this process. On the other hand, in $A$. thaliana during dark-induced senescence, three cytosolic glutamine synthetase genes are not expressed, in contrast to developmental senescence (Buchanan-Wollaston et al., 2005). The mentioned enzymes have a pivotal role in $\mathrm{N}$ mobilization, which may imply that different pathways may operate during differentially triggered senescence. The upregulated genes also observed only in DILS in barley are ones encoding aminotransferases (Sobieszczuk-Nowicka et al., 2018). The release of branched-chain amino acids confirms this upregulation during dark incubation of Arabidopsis leaves, which counteracts the toxicity of free ammonia from amino acids with a high $\mathrm{N}$ :C ratio (Law et al., 2018). Interestingly, genes responsible for proteolysis are differentially expressed in DILS and developmental senescence. During DILS in barley, for example, ubiquitin-conjugated enzyme is down-regulated while during development this enzyme is overexpressed. Similarly, an opposite expression profile can be observed for a vacuolar-processing enzyme precursor (changes in VPE are discussed in more detail in the section on autophagy), which is overexpressed during DILS whereas in developmental senescence it is down-regulated (Sobieszczuk-Nowicka et al., 2018). Also some members of subtilases - a family of serine-rich proteases (SPs) - can be differentially expressed in barley depending on the type of senescence. Subtilases in DILS, denoted HvSBT45, compared to developmental senescence were down-regulated during late stages of DILS, while in developmental senescence their expression level rises (Christiansen and Gregersen, 2014; Sobieszczuk-Nowicka et al., 2018). Roberts et al. (2017) tested gene expression of eleven subtilases in barley plants subjected to developmental and dark-induced senescence. They demonstrated that two out of all tested enzymes ( $H v S B T 3$ and HvSBT6) are upregulated in both senescence conditions, while one differentiated developmental and dark-induced senescence. HvSBT2 is only up-regulated during dark-induced senescence (Roberts et al., 2017). This shows that different subgroups of proteases take part in proteolysis, depending on the type of factor inducing senescence. Lastly, the RNA methylation index is higher in DILS than in developmental senescence, showing an increase in gene expression of for example RNA 2-O-methyltransferase fibrillarin two during DILS and inhibition during developmental senescence (Sobieszczuk-Nowicka et al., 2018; OstrowskaMazurek et al., 2020). 


\section{THE DARK-INDUCED LEAF SENESCENCE CROP MODEL AND ITS POINT OF NO RETURN - A SUMMARY}

There has been developed a crop model that demonstrates and explains early and late events of DILS and identifies the time limit for dark to light transition for reversal of the induced-senescence process within a leaf - DILS. DILS in barley occurs in two phases. The first phase is more strongly emphasized by cessation of photosynthesis, loss of chlorophyll, and disintegration of chloroplasts. Disintegration of chloroplasts correlated with the degradation of Rubisco and PsbA-D1 proteins. Despite the advanced state of macroautophagy in this phase, the processes of degradation turned out to be reversible. The reversal of DILS program involves regaining photosynthesis and increase of chlorophyll content, and it takes place irrespectively of the activation of ATG genes. The second, terminal phase, occurring beyond day 7 of darkness, is characterized by irreversibility of senescence and its progression into PCD, exemplified by the involvement of both autophagy and PCD pathways, and involves disruption of the nucleus, mitochondria, chromatin condensation accompanied with nDNA fragmentation, shrinking of the protoplast, tonoplast interruption, and disintegration of the cell membrane.

Non-invasive methods for quantifying photosynthetic efficiency and barley leaf nitrogen status established the time frame during which DILS enters the irreversible phase. Rfd is determined there as the earliest parameter that correlated well with the cessation of photosynthesis, together with the appearance of micro-autophagy symptoms. DILS program is

\section{REFERENCES}

Araujo, W. L., Ishizaki, K., Nunes-Nesi, A., Larson, T. R., Tohge, T., Krahnert, I., et al. (2010). Identification of the 2-hydroxyglutarate and isovaleryl-CoA dehydrogenases as alternative electron donors linking lysine catabolism to the electron transport chain of Arabidopsis mitochondria. Plant Cell 22, 1549-1563. doi: $10.1105 /$ tpc.110.075630

Arnao, M. B., and Hernández-Ruiz, J. (2009). Protective effect of melatonin against chlorophyll degradation during the senescence of barley leaves. J. Pineal Res. 46, 58-63.

Avila-Ospina, L., Marmagne, A., Soulay, F., and Masclaux-Daubresse, C. (2016). Identification of barley (Hordeum vulgare L.) autophagy genes and their expression levels during leaf senescence, chronic nitrogen limitation and in response to dark exposure. Agronomy 6:15.

Avila-Ospina, L., Marmagne, A., Talbotec, J., Krupinska, K., and MasclauxDaubresse, C. (2015). The identification of new cytosolic glutamine synthetase and asparagine synthetase genes in barley (Hordeum vulgare L.), and their expression during leaf senescence. J. Exp. Bot. 66, 2013-2026. doi: 10.1093/jxb/ erv003

Avila-Ospina, L., Moison, M., Yoshimoto, K., and Masclaux-Daubresse, C. (2014). Autophagy, plant senescence, and nutrient recycling. J. Exp. Bot. 65, 3799-3811. doi: $10.1093 /$ jxb/eru039

Baker, N. R., and Oxborough, K. (2004). "Chlorophyll fluorescence as a probe of photosynthetic productivity," in Chlorophyll a Fluorescence: A Signature of Photosynthesis, eds G. C. Papageorgiou and K. Govindjee (Dordrecht: Springer), 65-82.

Bassham, D. C., Laporte, M., Marty, F., Moriyasu, Y., Ohsumi, Y., Olsen, L. J., et al. (2006). Autophagy in development and stress responses of plants. Autophagy 2, 2-11. doi: 10.4161/auto.2092 also found to be characterized by the upregulation of processes that enable the recycling of degraded metabolites in darkness, including increased $\mathrm{NH}_{4}^{+}$remobilization, gluconeogenesis, glycolysis, and partial upregulation of glyoxylate and tricarboxylate acid cycles.

\section{AUTHOR CONTRIBUTIONS}

ES-N conceived the topic of the manuscript. EP-L, ES, and ES-N wrote the manuscript. EP-L prepared the figures. ES was responsible for the layout of the manuscript and prepared the table. ES-N coordinated writing of the manuscript. All authors listed have made a substantial, direct and intellectual contribution to the work, and approved it for publication.

\section{FUNDING}

The publication was co-financed within the National Science Centre, Poland (Project Numbers 2018/29/B/NZ9/00734 and 2018/30/E/NZ9/00827 to ES-N and 2017/27/N/NZ9/02135 to EP-L).

\section{ACKNOWLEDGMENTS}

We thank Richard Ashcroft (bioscience editor) for the professional language editing of the manuscript. We thank Krzysztof Polcyn for preparing the graphics for Figure 2.

Becker, W., and Apel, K. (1993). Differences in gene expression between natural and artificially induced leaf senescence. Planta 189, 74-79.

Bhalerao, R., Keskitalo, J., Sterky, F., Erlandsson, R., Bjorkbacka, H., Birve, S. J., et al. (2003). Gene expression in autumn leaves. Plant Physiol. 131, 430-442. doi: 10.1104/pp.012732

Bollhöner, B., Prestele, J., and Tuominen, H. (2012). Xylem cell death: emerging understanding of regulation and function. J. Exp. Bot. 63, 1081-1094. doi: $10.1093 / \mathrm{jxb} / \mathrm{err} 438$

Borek, S., Paluch-Lubawa, E., Pukacka, S., Pietrowska-Borek, M., and Ratajczak, L. (2017). Asparagine slows down the breakdown of storage lipid and degradation of autophagic bodies in sugar-starved embryo axes of germinating lupin seeds. J. Plant Physiol. 209, 51-67. doi: 10.1016/j.jplph.2016.10.016

Borek, S., Ruta-Piosik, M., Paluch, E., and Pietrowska-Borek, M. (2015). Selective kinds of autophagy. Postepy Biol. Komorki 42, 505-538.

Breeze, E., Harrison, E., McHattie, S., Hughes, L., Hickman, R., Hill, C., et al. (2011). High-resolution temporal profiling of transcripts during Arabidopsis leaf senescence reveals a distinct chronology of processes and regulation. Plant Cell 23, 873-894. doi: 10.1105/tpc.111.083345

Buchanan-Wollaston, V., Earl, S., Harrison, E., Mathas, E., Navabpour, S., Page, T., et al. (2003). The molecular analysis of leaf senescence - a genomics approach. Plant Biotechnol. J. 1, 3-22. doi: 10.1046/j.1467-7652.2003.00004.x

Buchanan-Wollaston, V., Page, T., Harrison, E., Breeze, E., Lim, P. O., Nam, H. G., et al. (2005). Comparative transcriptome analysis reveals significant differences in gene expression and signalling pathways between developmental and dark/starvation-induced senescence in Arabidopsis. Plant J. 42, 567-585. doi: 10.1111/j.1365-313X.2005.02399.x

Canetti, L., Lomaniec, E., Elkind, Y., and Lers, A. (2002). Nuclease activities associated with dark-induced and natural leaf senescence in parsley. Plant Sci. 163, 873-880. doi: 10.1016/S0168-9452(02)00242-X 
Cartelat, A., Cerovic, Z. G., Goulas, Y., Meyer, S., Lelarge, C., Prioul, J. L., et al. (2005). Optically assessed contents of leaf polyphenolics and chlorophyll as indicators of nitrogen deficiency in wheat (Triticum aestivum L.). Field Crops Res. 91, 35-49. doi: 10.1016/j.fcr.2004.05.002

Chiba, A., Ishida, H., Nishizawa, N. K., Makino, A., and Mae, T. (2003). Exclusion of ribulose-1,5-bisphosphate carboxylase/oxygenase from chloroplasts by specific bodies in naturally senescing leaves of wheat. Plant Cell Physiol. 44, 914-921. doi: 10.1093/pcp/pcg118

Christiansen, M. W., and Gregersen, P. L. (2014). Members of the barley NAC transcription factor gene family show differential co-regulation with senescence-associated genes during senescence of flag leaves. J. Exp. Bot. 65, 4009-4022. doi: 10.1093/jxb/eru046

Christiansen, M. W., Holm, P. B., and Gregersen, P. L. (2011). Characterization of barley (Hordeum vulgare L.) NAC transcription factors suggests conserved functions compared to both monocots and dicots. BMC Res. Notes 4:302. doi: 10.1186/1756-0500-4-302

Christiansen, M. W., Matthewman, C., Podzimska-Sroka, D., O'Shea, C., Lindemose, S., Møllegaard, N. E., et al. (2016). Barley plants over-expressing the NAC transcription factor gene HvNAC005 show stunting and delay in development combined with early senescence. J. Exper. Bot. 67, 5259-5273. doi: 10.1093/jxb/erw286

Chrobok, D., Law, S. R., Brouwer, B., Linden, P., Ziolkowska, A., Liebsch, D., et al. (2016). Dissecting the metabolic role of mitochondria during developmental leaf senescence. Plant Physiol. 172, 2132-2153. doi: 10.1104/pp.16.01463

Chrost, B., Daniel, A., and Krupinska, K. (2004). Regulation of $\alpha$-galactosidase gene expression in primary foliage leaves of barley (Hordeum vulgare L.) during dark-induced senescence. Planta 218, 886-889.

Chrost, B., and Krupinska, K. (2000). Genes with homologies to known $\alpha$ galactosidases are expressed during senescence of barley leaves. Physiol. Plant. 110, 111-119.

Chung, T., Suttangkakul, A., and Vierstra, R. D. (2009). The ATG autophagic conjugation system in maize: ATG transcripts and abundance of the ATG8-lipid adduct are regulated by development and nutrient availability. Plant Physiol. 149, 220-234. doi: 10.1104/pp.108.126714

Conrad, K., Motyka, V., and Schlüter, T. (2007). Increase in activity, glycosylation and expression of cytokinin oxidase/dehydrogenase during the senescence of barley leaf segments in the dark. Physiol. Plant. 130, 572-579.

Dodge, J. D. (1970). Changes in chloroplast fine structure during the autumnal senescence of betula leaves. Ann. Bot. 34, 817-824. doi: 10.1093/oxfordjournals. aob.a084412

Feekes, W. (1941). De Tarwe en Haar Milieu. Groningen: Hoitsema.

Feller, U., Anders, I., and Mae, T. (2008). Rubiscolytics: fate of Rubisco after its enzymatic function in a cell is terminated. J. Exp. Bot. 59, 1615-1624. doi: 10.1093/jxb/erm 242

Floyd, B. E., Pu, Y., Soto-Burgos, J., and Bassham, D. C. (2015). "To Live or Die: autophagy in plants," in Plant Programmed Cell Death, eds A. N. Gunawardena and P. F. McCabe (Cham: Springer International Publishing), 269-300.

Foyer, C. H., Noctor, G., and Hodges, M. (2011). Respiration and nitrogen assimilation: targeting mitochondria-associated metabolism as a means to enhance nitrogen use efficiency. J. Exp. Bot. 62, 1467-1482. doi: 10.1093/jxb/ erq453

Fracheboud, Y., and Leipner, J. (2003). “The application of chlorophyll fluorescence to study light, temperature, and drought stress," in Practical Applications of Chlorophyll Fluorescence in Plant Biology, eds J. R. DeEll and P. M. A. Toivonen (Boston, MA: Springer), 125-150.

Fukami, K. (2002). Structure, regulation, and function of phospholipase C isozymes. J. Biochem. 131, 293-299. doi: 10.1093/oxfordjournals.jbchem. a003102

Gan, S., and Amasino, R. M. (1995). Inhibition of leaf senescence by autoregulated production of cytokinin. Science 270, 1986-1988. doi: 10.1126/science.270.5244. 1986

Gan, S., and Amasino, R. M. (1997). Making sense of senescence (molecular genetic regulation and manipulation of leaf senescence). Plant Physiol. 113, 313-319. doi: 10.1104/pp.113.2.313

Gepstein, S., Sabehi, G., Carp, M. J., Hajouj, T., Nesher, M. F., Yariv, I., et al. (2003). Large-scale identification of leaf senescence-associated genes. Plant J. 36, 629-642. doi: 10.1046/j.1365-313x.2003.01908.x
Gregersen, P. L., Holm, P. B., and Krupinska, K. (2008). Leaf senescence and nutrient remobilisation in barley and wheat. Plant Biol. 10(Suppl. 1), 37-49. doi: 10.1111/j.1438-8677.2008.00114.x

Guo, Y., and Gan, S. S. (2012). Convergence and divergence in gene expression profiles induced by leaf senescence and 27 senescence-promoting hormonal, pathological and environmental stress treatments. Plant Cell Environ. 35, 644655. doi: 10.1111/j.1365-3040.2011.02442.x

Hara-Nishimura, I., Hatsugai, N., Nakaune, S., Kuroyanagi, M., and Nishimura, M. (2005). Vacuolar processing enzyme: an executor of plant cell death. Curr. Opin. Plant Biol. 8, 404-408. doi: 10.1016/j.pbi.2005. 05.016

Himelblau, E., and Amasino, R. M. (2001). Nutrients mobilized from leaves of Arabidopsis thaliana during leaf senescence. J. Plant Physiol. 158, 1317-1323. doi: 10.1078/0176-1617-00608

Hollmann, J., Gregersen, P. L., and Krupinska, K. (2014). Identification of predominant genes involved in regulation and execution of senescenceassociated nitrogen remobilization in flag leaves of field grown barley. J. Exp. Bot. 65, 3963-3973. doi: 10.1093/jxb/eru094

Hörtensteiner, S., and Feller, U. (2002). Nitrogen metabolism and remobilization during senescence. J. Exp. Bot. 53, 927-937. doi: 10.1093/jexbot/53.370.927

Ishida, H., and Yoshimoto, K. (2008). Chloroplasts are partially mobilized to the vacuole by autophagy. Autophagy 4, 961-962. doi: 10.4161/auto.6804

Ishida, H., Yoshimoto, K., Izumi, M., Reisen, D., Yano, Y., Makino, A., et al. (2008). Mobilization of rubisco and stroma-localized fluorescent proteins of chloroplasts to the vacuole by an ATG gene-dependent autophagic process. Plant Physiol. 148, 142-155. doi: 10.1104/pp.108.122770

Jajić, I., Wiśniewska-Becker, A., Sarna, T., Jemioła-Rzemińska, M., and Strzałka, K. (2014). EPR spin labeling measurements of thylakoid membrane fluidity during barley leaf senescence. J. Plant Physiol. 171, 1046-1053.

Janawad, C. S., Jyothi, G., Manu, T., and Murali, R. (2012). Autophagy is the emerging role in plant defense against pathogen attack. Glob. J. Biol. Agric. Health Sci. 1, 33-39.

Janečková, H., Husičková, A., Lazár, D., Ferretti, U., Pospíšil, P., and Špundová, M. (2019). Exogenous application of cytokinin during dark senescence eliminates the acceleration of photosystem II impairment caused by chlorophyll b deficiency in barley. Plant Physiol. Biochem. 136, 43-51.

Jenkins, G. M., and Frohman, M. A. (2005). Phospholipase D: a lipid centric review. Cell Mol. Life Sci. 62, 2305-2316. doi: 10.1007/s00018-005-5195-z

Jing, H. C., Hille, J., and Dijkwel, P. P. (2003). Ageing in plants: conserved strategies and novel pathways. Plant Biol. 5, 455-464. doi: 10.1055/s-2003-44779

Jing, H. C., Sturre, M. J., Hille, J., and Dijkwel, P. P. (2002). Arabidopsis onset of leaf death mutants identify a regulatory pathway controlling leaf senescence. Plant J. 32, 51-63. doi: 10.1046/j.1365-313x.2002.01400.x

Jukanti, A. K., Heidlebaugh, N. M., Parrott, D. L., Fischer, I. A., McInnerney, K., and Fischer, A. M. (2008). Comparative transcriptome profiling of nearisogenic barley (Hordeum vulgare) lines differing in the allelic state of a major grain protein content locus identifies genes with possible roles in leaf senescence and nitrogen reallocation. New Phytol. 177, 333-349. doi: 10.1111/j.1469-8137. 2007.02270.x

Keech, O., Pesquet, E., Ahad, A., Askne, A., Nordvall, D., Vodnala, S. M., et al. (2007). The different fates of mitochondria and chloroplasts during darkinduced senescence in Arabidopsis leaves. Plant Cell Environ. 30, 1523-1534. doi: 10.1111/j.1365-3040.2007.01724.x

Kleber-Janke, T., and Krupinska, K. (1997). Isolation of cDNA clones for genes showing enhanced expression in barley leaves during dark-induced senescence as well as during senescence under field conditions. Planta 203, 332-340. doi: $10.1007 / \mathrm{s} 004250050199$

Kleessen, S., Araujo, W. L., Fernie, A. R., and Nikoloski, Z. (2012). Modelbased confirmation of alternative substrates of mitochondrial electron transport chain. J. Biol. Chem. 287, 11122-11131. doi: 10.1074/jbc.M111.310383

Krause, K., Falk, J., Humbeck, K., and Krupinska, K. (1998). Responses of the transcriptional apparatus of barley chloroplasts to a prolonged dark period and to subsequent reillumination. Physiol. Plant. 104, 143-152.

Krieger-Liszkay, A., Krupinska, K., and Shimakawa, G. (2019). The impact of photosynthesis on initiation of leaf senescence. Physiol. Plant 166, 148-164. doi: $10.1111 / \mathrm{ppl} .12921$

Krupinska, K., Mulisch, M., Hollmann, J., Tokarz, K., Zschiesche, W., Kage, H., et al. (2012). An alternative strategy of dismantling of the chloroplasts during 
leaf senescence observed in a high-yield variety of barley. Physiol. Plant 144, 189-200. doi: 10.1111/j.1399-3054.2011.01545.x

Kucharewicz, W., Distelfeld, A., Bilger, W., Müller, M., Munné-Bosch, S., Hensel, G., et al. (2017). Acceleration of leaf senescence is slowed down in transgenic barley plants deficient in the DNA/RNA-binding protein WHIRLY1. J. Exper. Bot. 68, 983-996.

Kuriyama, H., and Fukuda, H. (2002). Developmental programmed cell death in plants. Curr. Opin. Plant Biol. 5, 568-573. doi: 10.1016/s1369-5266(02)00305-9

Lamb, C. A., Yoshimori, T., and Tooze, S. A. (2013). The autophagosome: origins unknown, biogenesis complex. Nat. Rev. Mol. Cell Biol. 14, 759-774. doi: 10. 1038/nrm3696

Lambert, R., Quiles, F. A., Galvez-Valdivieso, G., and Piedras, P. (2017). Nucleases activities during French bean leaf aging and dark-induced senescence. J. Plant Physiol. 218, 235-242. doi: 10.1016/j.jplph.2017.08.013

Lan, W., and Miao, Y. (2019). "Chapter 15 - Autophagy and senescence," in Senescence Signalling and Control in Plants, eds M. Sarwat and N. Tuteja (New York, NY: Academic Press), 239-253.

Lancashire, P. D., Bleiholder, H., Boom, T. V. D., Langelüddeke, P., Stauss, R., Weber, E., et al. (1991). A uniform decimal code for growth stages of crops and weeds. Ann. Appl. Biol. 119, 561-601.

Law, S. R., Chrobok, D., Juvany, M., Delhomme, N., Linden, P., Brouwer, B., et al. (2018). Darkened leaves use different metabolic strategies for senescence and survival. Plant Physiol. 177, 132-150. doi: 10.1104/pp.18.00062

Lee, R. H., Wang, C. H., Huang, L. T., and Chen, S. C. (2001). Leaf senescence in rice plants: cloning and characterization of senescence up-regulated genes. J. Exp. Bot. 52, 1117-1121. doi: 10.1093/jexbot/52.358.1117

Legocka, J., and Zajchert, I. (1999). Role of spermidine in the stabilization of the apoprotein of the light-harvesting chlorophyll a/b-protein complex of photosystem II during leaf senescence process. Acta Physiol. Plant. 21, 127-132.

Lichtenthaler, H., Langsdorf, G., Lenk, S., and Buschmann, C. (2005). Chlorophyll fluorescence imaging of photosynthetic activity with the flashlamp fluorescence imaging system. Photosynthetica 43, 355-369. doi: 10.1007/ s11099-005-0060-8

Lichtenthaler, H. K., and Grumbach, K. H. (1974). Kinetic of lipoquinone and pigment synthesis in green Hordeum seedlings during an artificial day-night rhythm with a prolonged dark phase. Zeitschrift Naturforschung C 29, 532-540.

Liebsch, D., and Keech, O. (2016). Dark-induced leaf senescence: new insights into a complex light-dependent regulatory pathway. New Phytol. 212, 563-570. doi: $10.1111 / \mathrm{nph} .14217$

Lim, P. O., Kim, H. J., and Nam, H. G. (2007). Leaf senescence. Annu. Rev. Plant Biol. 58, 115-136. doi: 10.1146/annurev.arplant.57.032905.105316

Lin, J. F., and Wu, S. H. (2004). Molecular events in senescing Arabidopsis leaves. Plant J. 39, 612-628. doi: 10.1111/j.1365-313X.2004.02160.x

Liu, J. D., Goodspeed, D., Sheng, Z., Li, B., Yang, Y., Kliebenstein, D. J., et al. (2015). Keeping the rhythm: light/dark cycles during postharvest storage preserve the tissue integrity and nutritional content of leafy plants. BMC Plant Biol. 15:92. doi: 10.1186/s12870-015-0474-9

Liu, Y., Zhang, W., Zhang, K., You, Q., Yan, H., Jiao, Y., et al. (2017). Genome-wide mapping of DNase I hypersensitive sites reveals chromatin accessibility changes in Arabidopsis euchromatin and heterochromatin regions under extended darkness. Sci. Rep. 7:4093. doi: 10.1038/s41598-017-04524-9

Maillard, A., Diquelou, S., Billard, V., Laine, P., Garnica, M., Prudent, M., et al. (2015). Leaf mineral nutrient remobilization during leaf senescence and modulation by nutrient deficiency. Front. Plant Sci. 6:317. doi: 10.3389/fpls. 2015.00317

Martinez, D. E., Costa, M. L., Gomez, F. M., Otegui, M. S., and Guiamet, J. J. (2008a). 'Senescence-associated vacuoles' are involved in the degradation of chloroplast proteins in tobacco leaves. Plant J. 56, 196-206. doi: 10.1111/j.1365313X.2008.03585.x

Martinez, D. E., Costa, M. L., and Guiamet, J. J. (2008b). Senescence-associated degradation of chloroplast proteins inside and outside the organelle. Plant Biol. 10(Suppl. 1), 15-22. doi: 10.1111/j.1438-8677.2008.00089.x

Masclaux, C., Quillere, I., Gallais, A., and Hirel, B. (2001). The challenge of remobilisation in plant nitrogen economy. A survey of physio-agronomic and molecular approaches. Ann. Appl. Biol. 138, 69-81. doi: 10.1111/j.1744-7348. 2001.tb00086.x

Masclaux, C., Valadier, M. H., Brugiere, N., Morot-Gaudry, J. F., and Hirel, B. (2000). Characterization of the sink/source transition in tobacco (Nicotiana tabacum L.) shoots in relation to nitrogen management and leaf senescence. Planta 211, 510-518. doi: 10.1007/s004250000310

Masclaux-Daubresse, C., Reisdorf-Cren, M., Pageau, K., Lelandais, M., Grandjean, O., Kronenberger, J., et al. (2006). Glutamine synthetase-glutamate synthase pathway and glutamate dehydrogenase play distinct roles in the sink-source nitrogen cycle in tobacco. Plant Physiol. 140, 444-456. doi: 10.1104/pp.105. 071910

Matile, P. (1992). "Chloroplast senescence," in Crop Photosynthesis: Spatial and Temporal Determinants, eds N. R. Baker and N. Thomas (Amsterdam: Elsevier), 413-440.

Mattoo, A. K., Marder, J. B., and Edelman, M. (1989). Dynamics of the photosystem II reaction center. Cell 56, 241-246. doi: 10.1016/0092-8674(89)90897-0

Nam, H. G. (1997). The molecular genetic analysis of leaf senescence. Curr. Opin. Biotechnol. 8, 200-207. doi: 10.1016/S0958-1669(97)80103-6

Obara, K., Kuriyama, H., and Fukuda, H. (2001). Direct evidence of active and rapid nuclear degradation triggered by vacuole rupture during programmed cell death in zinnia. Plant Physiol. 125, 615-626. doi: 10.1104/pp.125.2.615

Ostrowska-Mazurek, A., Kasprzak, P., Kubala, S., Zaborowska, M., and Sobieszczuk-Nowicka, E. (2020). Epigenetic landmarks of leaf senescence and crop improvement. Int. J. Mol. Sci. 21:125. doi: 10.3390/ijms21145125

Otegui, M. S., Noh, Y. S., Martinez, D. E., Vila Petroff, M. G., Staehelin, L. A., Amasino, R. M., et al. (2005). Senescence-associated vacuoles with intense proteolytic activity develop in leaves of Arabidopsis and soybean. Plant J. 41, 831-844. doi: 10.1111/j.1365-313X.2005.02346.x

Parrott, D. L., Martin, J. M., and Fischer, A. M. (2010). Analysis of barley (Hordeum vulgare) leaf senescence and protease gene expression: a family C1A cysteine protease is specifically induced under conditions characterized by high carbohydrate, but low to moderate nitrogen levels. New Phytol. 187, 313-331. doi: $10.1111 / j .1469-8137.2010 .03278 . x$

Pascual, V., Cha, S., Gershwin, M. E., Capra, J. D., and Leung, P. S. (1994). Nucleotide sequence analysis of natural and combinatorial anti-PDC-E2 antibodies in patients with primary biliary cirrhosis. Recapitulating immune selection with molecular biology. J. Immunol. 152, 2577-2585.

Patel, S., Caplan, J., and Dinesh-Kumar, S. P. (2006). Autophagy in the control of programmed cell death. Curr. Opin. Plant Biol. 9, 391-396. doi: 10.1016/j.pbi. 2006.05.007

Peterson, L. W., and Huffaker, R. C. (1975). Loss of ribulose 1,5-Diphosphate carboxylase and increase in proteolytic activity during senescence of detached primary barley leaves. Plant Physiol. 55, 1009-1015. doi: 10.1104/pp.55.6.1009

Phillips, A. R., Suttangkakul, A., and Vierstra, R. D. (2008). The ATG12conjugating enzyme ATG10 is essential for autophagic vesicle formation in Arabidopsis thaliana. Genetics 178, 1339-1353. doi: 10.1534/genetics.107. 086199

Roberts, I. N., Veliz, C. G., Criado, M. V., Signorini, A., Simonetti, E., and Caputo, C. (2017). Identification and expression analysis of 11 subtilase genes during natural and induced senescence of barley plants. J. Plant Physiol. 211, 70-80. doi: 10.1016/j.jplph.2017.01.005

Rogers, H. J. (2015). "Senescence-associated programmed cell death," in Plant Programmed Cell Death, eds A. N. Gunawardena and P. F. McCabe (Cham: Springer International Publishing), 203-233.

Rolny, N., Costa, L., Carrion, C., and Guiamet, J. J. (2011). Is the electrolyte leakage assay an unequivocal test of membrane deterioration during leaf senescence? Plant Physiol. Biochem. 49, 1220-1227. doi: 10.1016/j.plaphy.2011.06.010

Rosiak-Figielek, B., and Jackowski, G. (2000). The disappearance kinetics of Lhcb polypeptides during dark-induced senescence of leaves. Funct. Plant Biol. 27, 245-251.

Roulin, S., Buchala, A. J., and Fincher, G. B. (2002). Induction of $(1 \rightarrow 3,1 \rightarrow 4)$ ß-D-glucan hydrolases in leaves of dark-incubated barley seedlings. Planta 215 , 51-59.

Ruberti, C., Barizza, E., Bodner, M., La Rocca, N., De Michele, R., Carimi, F., et al. (2014). Mitochondria change dynamics and morphology during grapevine leaf senescence. PLoS One 9:e102012. doi: 10.1371/journal.pone.0102012

Sakamoto, W., and Takami, T. (2014). Nucleases in higher plants and their possible involvement in DNA degradation during leaf senescence. J. Exper. Bot. 65, 3835-3843. doi: 10.1093/jxb/eru091

Scharrenberg, C., Falk, J., Quast, S., Haussühl, K., Humbeck, K., and Krupinska, K. (2003). Isolation of senescence-related cDNAs from flag leaves of field grown barley plants. Physiol. Plant. 118, 278-288. 
Scheumann, V., Schoch, S., and Rüdiger, W. (1999). Chlorophyll b reduction during senescence of barley seedlings. Planta 209, 364-370.

Schippers, J. H., Schmidt, R., Wagstaff, C., and Jing, H. C. (2015). Living to die and dying to live: the survival strategy behind leaf senescence. Plant Physiol. 169, 914-930. doi: 10.1104/pp.15.00498

Shi, R., Weber, G., Köster, J., Reza-Hajirezaei, M., Zou, C., Zhang, F., et al. (2012). Senescence-induced iron mobilization in source leaves of barley (Hordeum vulgare) plants. New Phytol. 195, 372-383.

Sienko, K., Poormassalehgoo, A., Yamada, K., and Goto-Yamada, S. (2020). Microautophagy in plants: consideration of its molecular mechanism. Cells 9:887. doi: $10.3390 /$ cells 9040887

Simova-Stoilova, L., Demirevska-Kepova, K., and Stoyanova, Z. (2002). Ribulose1, 5-bisphosphate carboxylase/oxygenase specific proteolysis in barley chloroplasts during dark induced senescence. Photosynthetica 40, 561-566.

Smart, C. M., Hosken, S. E., Thomas, H., Greaves, J. A., Blair, B. G., and Schuch, W. (1995). The timing of maize leaf senescence and characterisation of senescencerelated cDNAs. Physiol. Plant. 93, 673-682.

Sobieszczuk-Nowicka, E., Kubala, S., Zmienko, A., Malecka, A., and Legocka, J. (2015). From accumulation to degradation: reprogramming polyamine metabolism facilitates dark-induced senescence in barley leaf cells. Front. Plant Sci. 6:1198.

Sobieszczuk-Nowicka, E., Kubala, S., Zmienko, A., Małecka, A., and Legocka, J. (2016). From accumulation to degradation: reprogramming polyamine metabolism facilitates dark-induced senescence in barley leaf cells. Front. Plant Sci. 6:1198. doi: 10.3389/fpls.2015.01198

Sobieszczuk-Nowicka, E., Wieczorek, P., and Legocka, J. (2009). Kinetin affects the level of chloroplast polyamines and transglutaminase activity during senescence of barley leaves. Acta Biochim. Polon. 56, 255-259.

Sobieszczuk-Nowicka, E., Wrzesinski, T., Bagniewska-Zadworna, A., Kubala, S., Rucinska-Sobkowiak, R., Polcyn, W., et al. (2018). Physio-genetic dissection of dark-induced leaf senescence and timing its reversal in barley. Plant Physiol. 178, 654-671. doi: 10.1104/pp.18.00516

Springer, A., Acker, G., Bartsch, S., Bauerschmitt, H., Reinbothe, S., and Reinbothe, C. (2015). Differences in gene expression between natural and artificially induced leaf senescence in barley. J. Plant Physiol. 176, 180-191. doi: 10.1016/j. jplph.2015.01.004

Spundova, M., Popelkova, H., Ilik, P., Skotnica, J., Novotny, R., and Naus, J. (2003). Ultra-structural and functional changes in the chloroplasts of detached barley leaves senescing under dark and light conditions. J. Plant Physiol. 160, 1051-1058. doi: 10.1078/0176-1617-00902

Stefaniak, S., Wojtyla, L., Pietrowska-Borek, M., and Borek, S. (2020). Completing autophagy: formation and degradation of the autophagic body and metabolite salvage in plants. Int. J. Mol. Sci. 21:2205. doi: 10.3390/ijms21062205

Thomas, H. (2013). Senescence, ageing and death of the whole plant. New Phytol. 197, 696-711. doi: 10.1111/nph.12047

Thomas, H., and Ougham, H. (2014). The stay-green trait. J. Exp. Bot. 65, 38893900. doi: $10.1093 / \mathrm{jxb} / \mathrm{eru} 037$

Uauy, C., Distelfeld, A., Fahima, T., Blechl, A., and Dubcovsky, J. (2006). A NAC gene regulating senescence improves grain protein, zinc, and iron content in wheat. Science 314, 1298-1301. van der Graaff, E., Schwacke, R., Schneider, A., Desimone, M., Flugge, U. I., and Kunze, R. (2006). Transcription analysis of arabidopsis membrane transporters and hormone pathways during developmental and induced leaf senescence. Plant Physiol. 141, 776-792. doi: 10.1104/pp.106.079293

van Doorn, W. G., and Woltering, E. J. (2005). Many ways to exit? Cell death categories in plants. Trends Plant Sci. 10, 117-122. doi: 10.1016/j.tplants.2005. 01.006

van Doorn, W. G., and Yoshimoto, K. (2010). Role of chloroplasts and other plastids in ageing and death of plants and animals: a tale of Vishnu and Shiva. Age. Res. Rev. 9, 117-130. doi: 10.1016/j.arr.2009.08.003

Wang, P., Mugume, Y., and Bassham, D. C. (2018). New advances in autophagy in plants: regulation, selectivity and function. Semin. Cell Dev. Biol. 80, 113-122. doi: 10.1016/j.semcdb.2017.07.018

Wehner, G. G., Balko, C. C., Enders, M. M., Humbeck, K. K., and Ordon, F. F. (2015). Identification of genomic regions involved in tolerance to drought stress and drought stress induced leaf senescence in juvenile barley. BMC Plant Biol. 15:125. doi: 10.1186/s12870-015-0524-3

Wong, S.-L., Chen, C.-W., Huang, M.-Y., and Weng, J.-H. (2014). Relationship between photosynthetic $\mathrm{CO}_{2}$ uptake rate and electron transport rate in two $\mathrm{C} 4$ perennial grasses under different nitrogen fertilization, light and temperature conditions. Acta Physiol. Plant. 36, 849-857. doi: 10.1007/s11738-013$1463-\mathrm{y}$

Wood, M., Power, J. B., Davey, M. R., Lowe, K. C., and Mulligan, B. J. (1998). Factors affecting single strand-preferring nuclease activity during leaf aging and dark-induced senescence in barley (Hordeum vulgare L.). Plant Sci. 131, 149-159. doi: 10.1016/S0168-9452(97)0 0253-7

Xia, T., Xiao, D., Liu, D., Chai, W., Gong, Q., and Wang, N. N. (2012). Heterologous expression of $A T G 8 c$ from soybean confers tolerance to nitrogen deficiency and increases yield in Arabidopsis. PLoS One 7:e37217. doi: 10.1371/journal.pone. 0037217

Żelisko, A., and Jackowski, G. (2004). Senescence-dependent degradation of Lhcb3 is mediated by a thylakoid membrane-bound protease. J. Plant Physiol. 161, $1157-1170$.

Zmienko, A., Samelak-Czajka, A., Goralski, M., Sobieszczuk-Nowicka, E., Kozlowski, P., and Figlerowicz, M. (2015). Selection of reference genes for qPCR-and ddPCR-based analyses of gene expression in senescing barley leaves. PLoS One 10:e0118226. doi: 10.1371/journal.pone.00118226

Conflict of Interest: The authors declare that the research was conducted in the absence of any commercial or financial relationships that could be construed as a potential conflict of interest.

Copyright (๑) 2021 Paluch-Lubawa, Stolarska and Sobieszczuk-Nowicka. This is an open-access article distributed under the terms of the Creative Commons Attribution License (CC BY). The use, distribution or reproduction in other forums is permitted, provided the original author(s) and the copyright owner(s) are credited and that the original publication in this journal is cited, in accordance with accepted academic practice. No use, distribution or reproduction is permitted which does not comply with these terms. 